\title{
Development and Validation of Chromatographic and Spectrophotometric Methods for the Quantitation of Rufinamide in Pharmaceutical Preparations
}

\author{
(1) Habibur RAHMAN1, (1) SK Manirul HAQUE2* \\ 1Jubail Industrial College, Royal Commission of Jubail, Department of General Studies, Al Jubail, Saudi Arabia \\ 2Jubail Industrial College, Royal Commission of Jubail, Department of Chemical Engineering, Al Jubail, Saudi Arabia
}

\begin{abstract}
Objectives: Two optimized and validated high performance liquid chromatography (HPLC) and spectrophotometric methods are proposed. The developed methods were quantified with high sensitivity, accuracy, and precision at low concentrations to determine rufinamide (RUF) in active pharmaceutical ingredients (API) and pharmaceutical preparations.

Materials and Methods: HPLC method was developed using a base deactivated silica Hypersil $\mathrm{C}_{18}$ column and a combination of methanol: acetonitrile: water (15: 10: 75, v/v/v) as the mobile phase and detected at $210 \mathrm{~nm}$. A reaction of RUF with sodium nitrite and hydrochloric acid occurred, absorbed maximally at $385 \mathrm{~nm}$ was extended to develop a ultraviolet (UV)-visible spectrophotometric method to determine RUF in API and pharmaceutical preparations.

Results: Different analytical validation parameters, including specificity, linearity, accuracy, precision, the limit of detection, quantification, ruggedness, and robustness, were determined as per International Conference on Harmonization guidelines. The linearity range of RUF was 0.153.5 and $10-100 \mu \mathrm{g} / \mathrm{mL}$ for HPLC and spectrophotometric methods, respectively.

Conclusion: The proposed investigations were valuable for drug monitoring and regular analysis of RUF in quality control and research laboratories. Moreover, the accuracy and precision obtained with the UV-visible spectrophotometer implied that it could be a cheap, easy, and alternative method, while HPLC could be sensitive to determine RUF at low concentration levels.
\end{abstract}

Key words: Rufinamide, validation, quality control laboratories, HPLC, UV-visible spectrophotometry

\section{INTRODUCTION}

Rufinamide (RUF) is a third-generation antiepileptic drug used to treat a neurological disorder characterized by seizure symptoms linked to Lennox-Gastaut syndrome (LGS). LGS is rare and one of the most severe forms of epilepsy among children between typically 3 to 5 years and adults. Therefore, the treatmeant of LGS is highly important, particularly in patients with childhood epilepsy. However, treatment success is limited by this condition.1.2 RUF is a triazole derivative classified as an orphan drug, chemically known as 1-[(2,6-difluorophenyl) methyl]-1H-1,2,3-triazole-4 carboxamide (mol. formula:
$\mathrm{C}_{10} \mathrm{H}_{8} \mathrm{~F}_{2} \mathrm{~N}_{4} \mathrm{O}, \mathrm{MW}: 238.2 \mathrm{~g} / \mathrm{mol}$ ) developed in 2004 and has been authorized by the US Food and Drug Administration (US FDA) in 2008 for managing seizures associated with LGS $^{3-8}$ in children ( 4 years and above) and adults. RUF is believed to increase the refractory period of voltage-dependent sodium channels, reducing the possibility of fire in neurons. ${ }^{9}$ The carboxamide group of RUF is extensively metabolized via carboxylesterasemediated hydrolysis in a pharmacologically inactive carboxylic acid derivative and finally excreted in the urine. It has been recommended to monitor the absorption of this drug (slow and dose-dependent), as its peculiar and probable interaction with 
co-administered antiepileptic agents leads to pharmacokinetic variability. Therefore, regular therapeutic drug monitoring must adjust optimal dosage according to the patient's individual needs with epileptic seizures. ${ }^{10}$ Chromatographic methods with different detection techniques, such as high performance liquid chromatography/ultraviolet (HPLC/UV) and liquid chromatography-tandem mass spectrometry ${ }^{11-25}$ (LC-MS) have been developed. Recently, stability-indicating reversed phase-HPLC and first derivative ratio assays were designed to determine RUF in the presence of an alkaline degradation product in dosage forms. ${ }^{26}$ A validated high-performance thin-layer chromatographic (TLC) assay in bulk drug and its formulations were also developed. ${ }^{27}$ Only a few low sensitive spectrophotometric methods in pharmaceutical dosage forms, human and animal biological fluids, ${ }^{28-30}$ and extraction-based spectrophotometric methods have been developed to determine RUF. 31,32

Most reported methods have several drawbacks and are not stability-indicating. Hence, there is a need to develop sensitive, validated, and simple analytical methodologies such as HPLC and UV-visible spectrophotometry, which are widely employed in pharmaceutical quality control laboratories to quantify drug substances, and to estimate accurate and precise drug content in pharmaceutical preparations. HPLC method is characterized by sensitivity, repeatability, specificity, and spectrophotometric techniques, considered inexpensive, simple, fast, and direct.

This research aimed to develop two well-optimized and validated analytical methods (HPLC and spectrophotometry) with high sensitivity, accuracy, and precision with a good linearity range for RUF determination in pure and pharmaceutical preparations.

\section{MATERIALS AND METHODS}

\section{Products and reagents}

Sodium nitrite $\left(\mathrm{NaNO}_{2}\right)$, hydrochloric acid $(\mathrm{HCl})$, methanol $\left(\mathrm{CH}_{3} \mathrm{OH}\right)$, dimethylformamide $\left[\left(\mathrm{CH}_{3}\right)_{2} \mathrm{NCH}\right]$, and acetonitrile $\left(\mathrm{CH}_{3} \mathrm{CN}\right)$ were purchased from Sigma Aldrich through a local vendor. All the reagents are analytical grade and can be utilized without additional purification. Banzel 200 and $400 \mathrm{mg}$ of the pharmaceutical product belonged to Eisai Co. Ltd.

\section{Instrumentation and analytical conditions}

Shimadzu, LC-2010 CHT HPLC was used to separate, which consists of a pump (LC-20AD), autosampler (SIL-20AC), column oven (CTO-20AC), and photodiode array detector (SPD-20A). LC solution software was used to integrate the chromatograms. The column used to separate the analytes was base-deactivated silica (BDS) Hypersil $C_{18}(250 \mathrm{~mm} \times 4.6 \mathrm{~mm}, 5 \mu \mathrm{m})$. The column temperature was maintained at $30^{\circ} \mathrm{C}$ with a mobile phase comprised methanol: acetonitrile: dimethylformamide (7:5:8, $\mathrm{v} / \mathrm{v} / \mathrm{v})$ with a fixed flow rate $(1 \mathrm{~mL} / \mathrm{min})$. An injection volume of $10 \mu \mathrm{L}$ was chosen and detected at $210 \mathrm{~nm}$. All the spectral runs were performed using Jenway (UV-vis 6300) and cecil (CE-7400) spectrophotometers with $10 \mathrm{~mm}$ path length at a wavelength of $385 \mathrm{~nm}$.

\section{Extraction of RUF from the dosage forms}

Five RUF tablets $(200 \mathrm{mg} /$ tablet $)$ were ground into powder, shifted into a $1000 \mathrm{~mL}$ beaker and dissolved in dimethylformamide and distilled water (1: 10). Stationary phase used in column chromatography was silica gel. Mobile phase consisted of methanol: water: glacial acetic acid (6.3: 1.3: 0.5 v/v/v), separated and dried as a solid RUF.

\section{Preparation of standard solutions}

For HPLC method, RUF stock solution $(50 \mu \mathrm{g} / \mathrm{mL}$ ) was prepared in a $100 \mathrm{~mL}$ volumetric flask by transferring the correct amount of the drug in dimethylformamide (DMF). Then, sonicated the mixture was for $15 \mathrm{~min}$, and finally, the volume was completed with DMF. This solution was further diluted as per the requirement of the analysis.

A stock of RUF (1 $\mathrm{mg} / \mathrm{mL}$ ) was prepared for the spectrophotometric method in DMF. The $\mathrm{HCl}(0.50 \mathrm{M})$ and $\mathrm{NaNO}_{2}(0.10 \mathrm{M})$ were diluted and prepared with distilled water, and further dilutions were continued as necessary.

\section{Optimization of variables}

Trial of current HPLC procedure was performed using several columns such as ODS Hypersil $C_{18}(250 \mathrm{~mm} \times 4.6 \mathrm{~mm}, 5 \mu \mathrm{m})$, ODS Hypersil $C_{18}(150 \mathrm{~mm} \times 4.6 \mathrm{~mm}, 5 \mu \mathrm{m})$, ODS Hypersil $\mathrm{C}_{8}$ (250 mm × $4.6 \mathrm{~mm}, 5 \mu \mathrm{m})$, ODS Hypersil $\mathrm{C}_{8}(150 \mathrm{~mm} \times 4.6$ $\mathrm{mm}, 5 \mu \mathrm{m})$, BDS Hypersil $C_{18}(250 \mathrm{~mm} \times 4.6 \mathrm{~mm}, 5 \mu \mathrm{m})$, BDS Hypersil $C_{18}(150 \mathrm{~mm} \times 4.6 \mathrm{~mm}, 5 \mu \mathrm{m})$, BDS Hypersil $C_{8}(250$ $\mathrm{mm} \times 4.6 \mathrm{~mm}, 5 \mu \mathrm{m})$, and BDS Hypersil $C_{8}(150 \mathrm{~mm} \times 4.6 \mathrm{~mm}$, $5 \mu \mathrm{m})$. The best separation was achieved with BDS Hypersil $\mathrm{C}_{8}$ (250 mm $\times 4.6 \mathrm{~mm}, 5 \mu \mathrm{m}$ ). Different solvents with ratio, as the mobile phase, were studied and the highest separation occurs with methanol: acetonitrile: dimethylformamide (7: 5: 8, v/v/v) at a controlled oven temperature $30^{\circ} \mathrm{C}$ with detection at $210 \mathrm{~nm}$.

Effect of volume of $0.50 \mathrm{M} \mathrm{HCl}$ concentration was studied using spectrophotometry by keeping a constant concentration of RUF $(100 \mu \mathrm{g} / \mathrm{mL})$ and $1 \mathrm{~mL} \mathrm{NaNO}{ }_{2}(0.10 \mathrm{M})$ with a varied concentration of $\mathrm{HCl}(0.1-1.1 \mathrm{~mL})$ in a final volume of $10 \mathrm{~mL}$ solution. Similarly, influence of $0.10 \mathrm{M} \mathrm{NaNO}_{2}$ solution concentration was also studied by keeping the constant concentrations of RUF (100 $\mu \mathrm{g} / \mathrm{mL}$ ) and the optimized concentration of $0.50 \mathrm{M} \mathrm{HCl}(0.9$ $\mathrm{mL}$ ) and varying the concentration of $\mathrm{NaNO}_{2}(0.1-2.4 \mathrm{~mL})$ in a final volume of $10 \mathrm{~mL}$ solution. Figure 1 shows an increase in the absorbance of $0.5 \mathrm{M} \mathrm{HCl}$ concentration up to $0.7 \mathrm{~mL}$ and the influence of $0.10 \mathrm{M} \mathrm{NaNO}_{2}$ solution concentration on the absorbance up to $1.8 \mathrm{~mL}$. Therefore, concentrations of $0.9 \mathrm{~mL}$ of $0.50 \mathrm{M} \mathrm{HCl}$ and $2.1 \mathrm{~mL}$ of $0.1 \mathrm{M} \mathrm{NaNO}_{2}$ were used throughout the experiment. The figure also includes an error bar with the respective standard deviations for optimizing $\mathrm{HCl}$ and $\mathrm{NaNO}_{2}$.

\section{Analytical method validation}

The optimized spectrophotometric method was validated by evaluating the linearity, accuracy, precision, the limit of detection (LOD), the limit of quantitation ( $L O Q$ ), specificity, standard addition, ruggedness, and robustness following the International Conference on Harmonization (ICH) guideline Q2 (R1). ${ }^{33}$ 


\section{Linearity}

Aliquots of $0.1-1.0 \mathrm{~mL}$ from $100 \mu \mathrm{g} / \mathrm{mL}$ RUF were pipetted into a series of $10 \mathrm{~mL}$ standard volumetric flasks. To each flask, $0.9 \mathrm{~mL}$ of $0.50 \mathrm{M} \mathrm{HCl}$ was added, followed by $2.1 \mathrm{~mL}$ of $0.10 \mathrm{M}$ $\mathrm{NaNO}_{2}$. The volume was completed with double distilled water. The contents of each flask were mixed well and heated at $100^{\circ} \mathrm{C}$. The increase in absorbance was recorded immediately at $385 \mathrm{~nm}$.

Into a sequence of ten volumetric flasks with a $50 \mathrm{~mL}$ capacity, different RUF $(50 \mu \mathrm{g} / \mathrm{mL})$ volumes were transferred to prepare in the range of $0.15-3.5 \mu \mathrm{g} / \mathrm{mL}$. $10 \mu \mathrm{L}$ of each one was injected in 5 replicates and average peak area was recorded to evaluate the developed method's linearity range.

\section{$\angle O D$ and $\angle O Q$}

Both methods (spectrophotometric and HPLC) sensitivities were established with the LOD and the LOQ. The LOD and LOQ values were computed with the help of a calibration curve, following the equations given below:

$\mathrm{LOD}=3.3 \times \mathrm{S}_{0} / \mathrm{m}$, and $\mathrm{LOQ}=10 \times \mathrm{S}_{0} / \mathrm{m}$,

where $\mathrm{S}_{0}=$ standard deviation of the $\mathrm{y}$-intercept of a regression line:

$\mathrm{m}=$ Slope of the calibration curve

\section{Accuracy and precision}

HPLC and spectrophotometric method's accuracy precision were assessed. It determines the drug concentration at three different concentration levels (low, medium and high) within one day (intraday) and 5 consecutive days (interday). The standard deviation (SD) and percentage relative SD (RSD\%) were determined. The standard addition method was continued to obtain percentage recoveries.

\section{Robustness}

For assessing method robustness, a slight variation was considered with the current experimental parameters. The

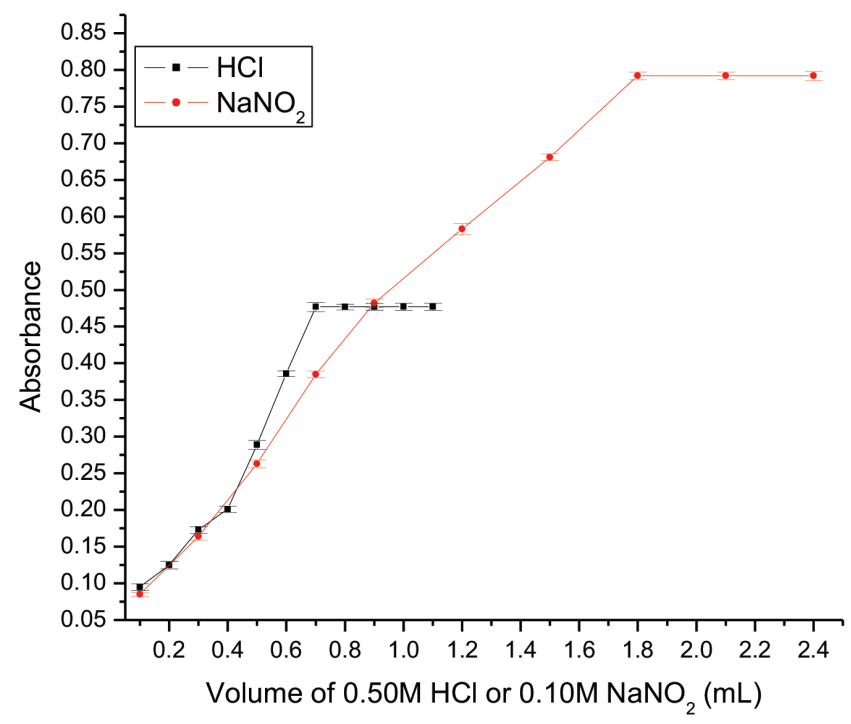

Figure 1. Effect of concentration and error bars with standard deviations of $\mathrm{HCl} / \mathrm{NaNO}_{2}$ analysis was presented at the deliberately varied experimental conditions using two wavelengths $( \pm 2 \mathrm{~nm}$ ) and a mobile phase composition ratio. SD and RSD\% were calculated.

\section{Ruggedness}

Small changes in the environment conducted experiments, and an instrument model means little variation with operating conditions than the standard proposed analysis method.

\section{Statistical analysis}

Detailed statistical data analyses are presented in Table 1 for the proposed methods. The results proved an outstanding correlation between peak area and each drug's concentration within the specified range.

\section{RESULTS AND DISCUSSION}

RUF, an US FDA-approved drug, is a triazole derivative structurally unrelated to other marketed antiepileptic drugs. It is highly susceptible to acidic and alkaline hydrolysis. Simultaneously, it remained stable under oxidative, thermal, and photolytic stress conditions. ${ }^{34}$ Literature reported that RUF could extensively metabolize after the hydrolysis of the carboxamide group of the drug via a primary biotransformation pathway (carboxylesterases) into an inactive acid derivative that is eliminated mainly in the urine. ${ }^{35,36}$ Based on the above facts, a reaction of RUF with $\mathrm{NaNO}_{2}$ and $\mathrm{HCl}$ performed at $100^{\circ} \mathrm{C}$ undergoes hydrolysis of the carboxamide group of the drug and is expected to convert into a yellow-coloured acid derivative that absorbs maximally at $385 \mathrm{~nm}$. A scheme was proposed based on a literature survey (Figure 2).

Under optimized chromatographic conditions, RUF was separated with a higher number of theoretical plates, good resolution, and peak shape. There was no interference from other components with a retention time of $4.65 \mathrm{~min}$ (Figure 3).

The specificity/system suitability test runs to ensure the current procedures connect all the requirements to start the analysis. Generally, it determines the presence of common excipients available with the pharmaceutical dosage form to know the

Table 1. Summary of linearity data for spectrophotometry and HPLC methods

\begin{tabular}{lll} 
Parameter & $\begin{array}{l}\text { UV-visible } \\
\text { spectrophotometry }\end{array}$ & HPLC \\
\hline $\begin{array}{l}\text { Beer's law range } \\
(\mu \mathrm{g} / \mathrm{mL})\end{array}$ & $10-100$ & $0.15-3.5$ \\
\hline Regression equation & $\mathrm{y}=0.0078 \mathrm{x}-0.0059$ & $\mathrm{y}=2332.2 \mathrm{x}+970.72$ \\
\hline $\mathrm{S}_{0}$ & 0.009697 & 42.82088 \\
\hline $\mathrm{M}($ slope $)$ & 0.007863 & 2332.155 \\
\hline $\begin{array}{l}\text { Regression } \\
\text { coefficient }\left(\mathrm{r}^{2}\right)\end{array}$ & 0.9984 & 0.9998 \\
\hline $\mathrm{LOD}(\mu \mathrm{g} / \mathrm{mL})$ & 4.07 & 0.061 \\
\hline $\mathrm{LOQ}(\mu \mathrm{g} / \mathrm{mL})$ & 12.33 & 0.184 \\
\hline
\end{tabular}

LOD: Limit of detection, LOQ: Limit of quantitation 
methods' ability to separate without interference. RSD\% was calculated for both practices and found to be less than $2 \%$.

Under optimized experimental conditions described, Beer's law obeyed the concentration ranges of $10-100 \mu \mathrm{g} / \mathrm{mL}$ for spectrophotometric method. The linear regression analysis used the least square method to assess the slope, intercept, and regression coefficient. High values of the regression coefficient and the small values of the regression equation intercept proved the calibration curve's linearity. The detection and quantification limit values reveal the proposed methods' high sensitivity. The HPLC procedure was rectilinear within 0.15-3.5 $\mu \mathrm{g} / \mathrm{mL}$.

$L O D$ and $L O Q$ are the smallest concentrations that provide a noticeable response and possibly be quantified. Consequently, signal to noise ratio was computed. Then, the current methods calculated the LOD and LOQ values of 0.061, 4.07, and 0.184, $12.33 \mu \mathrm{g} / \mathrm{mL}$, respectively. The replicated analysis $(n=5)$ of RUF corresponding to 1,2 , and 3 , as well as 20,60 , and $100 \mu \mathrm{g} /$ $\mathrm{mL}$ of the proposed HPLC and UV-visible spectrophotometric methods were performed, determining its intraday and interday
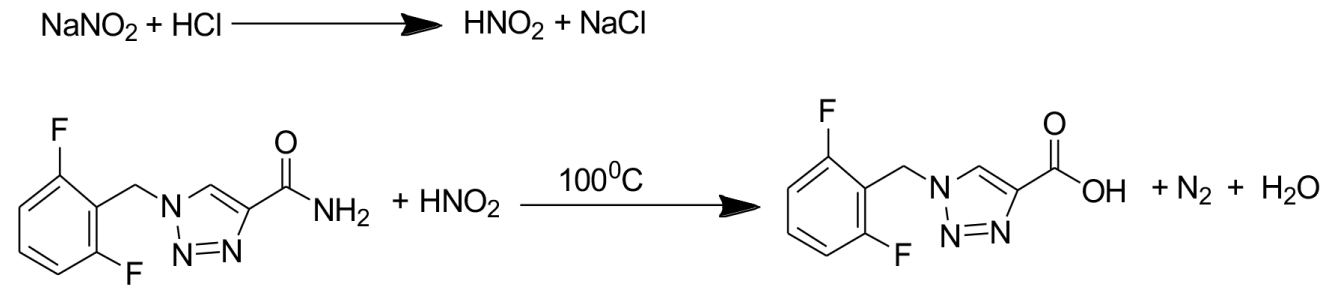

Figure 2. Proposed reaction scheme

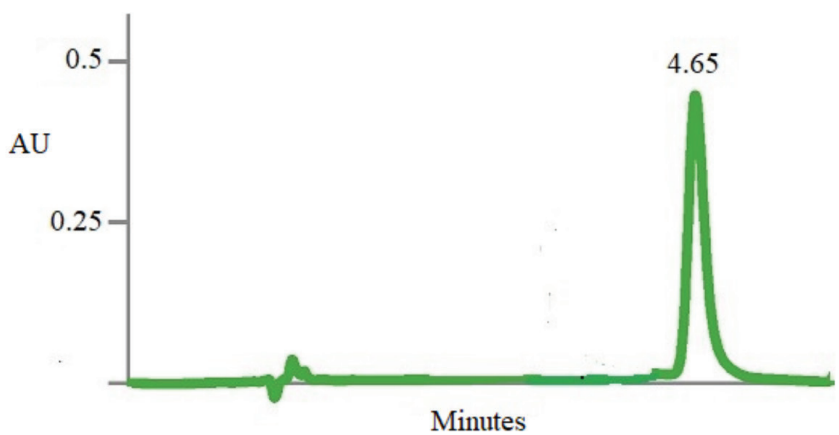

Figure 3. RUF chromatogram with a retention time of $4.65 \mathrm{~min}$

\section{Table 2. Determination of RUF in pharmaceutical formulations for precision}

\begin{tabular}{|c|c|c|c|c|c|c|c|}
\hline \multirow{2}{*}{ The proposed methods } & & \multicolumn{2}{|c|}{ Amount $(\mu \mathrm{g} / \mathrm{mL})$} & \multirow{2}{*}{ Recovery\% } & \multirow{2}{*}{$\mathrm{RSD} \%^{\mathrm{a}}$} & \multirow{2}{*}{$\mathrm{SAE}^{\mathrm{b}}$} & \multirow{2}{*}{$\mathrm{CL}^{\mathrm{c}}$} \\
\hline & & Taken & Found $\pm S D^{a}$ & & & & \\
\hline \multirow{4}{*}{$\begin{array}{l}\text { UV-visible } \\
\text { spectrophotometry }\end{array}$} & \multirow{2}{*}{ Intraday } & 20 & $19.67 \pm 0.112$ & 98.35 & 0.569 & 0.050 & 0.139 \\
\hline & & 100 & $99.81 \pm 0.101$ & 99.81 & 0.101 & 0.045 & 0.125 \\
\hline & \multirow{2}{*}{ Interday } & 20 & $19.63 \pm 0.125$ & 98.15 & 0.637 & 0.056 & 0.155 \\
\hline & & 100 & $99.56 \pm 0.131$ & 99.56 & 0.132 & 0.059 & 0.163 \\
\hline \multirow{4}{*}{ HPLC } & \multirow{3}{*}{ Intraday } & 1 & $0.989 \pm 0.005$ & 98.90 & 0.506 & 0.002 & 0.006 \\
\hline & & 2 & $1.987 \pm 0.006$ & 99.35 & 0.302 & 0.003 & 0.008 \\
\hline & & 3 & $2.963 \pm 0.009$ & 98.77 & 0.304 & 0.004 & 0.011 \\
\hline & Interday & 3 & $2.983 \pm 0.014$ & 99.43 & 0.469 & 0.006 & 0.017 \\
\hline
\end{tabular}

Mean for 5 independent analyses. ${ }^{a}$ SD: Standard deviation, RSD: Relative standard deviation, ${ }^{b} \mathrm{SAE}$ : Standard analytical error, ${ }^{\mathrm{C}} \mathrm{CL}$ : Confidence limit at $95 \%$ confidence level and 4 degrees of freedom $(t=2.776)$ 
Table 3. Standard addition method to determine accuracy of the proposed methods

\begin{tabular}{|c|c|c|c|c|c|c|c|c|}
\hline \multirow{2}{*}{\multicolumn{2}{|c|}{ The proposed methods }} & \multicolumn{3}{|c|}{ Amount $(\mu \mathrm{g} / \mathrm{mL})$} & \multirow{2}{*}{ \% Recovery } & \multirow{2}{*}{$\% \mathrm{RSD}^{\mathrm{a}}$} & \multirow{2}{*}{$\mathrm{SAE}^{\mathrm{b}}$} & \multirow{2}{*}{$\mathrm{CL}^{\mathrm{c}}$} \\
\hline & & Taken & Added & Found $\pm S D^{a}$ & & & & \\
\hline \multirow{6}{*}{$\begin{array}{l}\text { UV-visible } \\
\text { spectrophotometry }\end{array}$} & \multirow{3}{*}{ Intraday } & 20 & 20 & $39.75 \pm 0.145$ & 99.38 & 0.365 & 0.065 & 0.180 \\
\hline & & 20 & 40 & $59.92 \pm 0.123$ & 99.87 & 0.205 & 0.055 & 0.153 \\
\hline & & 20 & 60 & $78.99 \pm 0.132$ & 98.74 & 0.167 & 0.059 & 0.164 \\
\hline & \multirow{3}{*}{ Interday } & 20 & 20 & $39.88 \pm 0.167$ & 99.70 & 0.419 & 0.075 & 0.207 \\
\hline & & 20 & 40 & $59.64 \pm 0.153$ & 99.40 & 0.257 & 0.068 & 0.190 \\
\hline & & 20 & 60 & $79.11 \pm 0.148$ & 98.87 & 0.187 & 0.066 & 0.184 \\
\hline \multirow{6}{*}{ HPLC } & \multirow{3}{*}{ Intraday } & 0.8 & 0.8 & $1.58 \pm 0.003$ & 98.75 & 0.190 & 0.001 & 0.004 \\
\hline & & 0.8 & 1.6 & $2.39 \pm 0.004$ & 99.58 & 0.167 & 0.002 & 0.005 \\
\hline & & 0.8 & 2.4 & $3.17 \pm 0.007$ & 99.06 & 0.221 & 0.003 & 0.009 \\
\hline & \multirow{3}{*}{ Interday } & 0.8 & 0.8 & $1.57 \pm 0.006$ & 98.13 & 0.382 & 0.003 & 0.007 \\
\hline & & 0.8 & 1.6 & $2.38 \pm 0.009$ & 99.17 & 0.378 & 0.004 & 0.011 \\
\hline & & 0.8 & 2.4 & $3.19 \pm 0.005$ & 99.69 & 0.157 & 0.002 & 0.006 \\
\hline
\end{tabular}

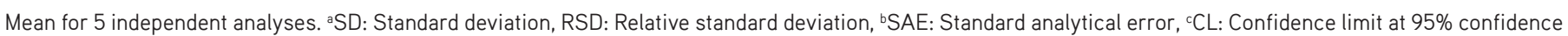
level and 4 degrees of freedom $(t=2.776)$

precision. For spectrophotometric and HPLC methods, the \% RSD was $0.101-0.637 \%$ and $0.302-0.807$, respectively (Table 2). The accuracy parameter was determined with help of the standard addition method. Due to that, 50,100, and 150\% were spiked with the original drug components and determined its \% recovery. The computed value was $98-100 \%$ for both methods (Table 3).

The method's robustness relative to each functioning parameter was studied and verified. The impacts of variation with wavelength $( \pm 2)$ and mobile phase composition ( \pm $2 \%$ ) were analyzed to determine the method's robustness. Recovery\% and RSD were 99.15-99.56 and 0.123-0.612\% for both methods.

Ruggedness studies were conducted with a different model of instrument. As per $\mathrm{ICH}$ guidelines, recovery $\% \pm \mathrm{RSD}$ resulted within 98-102 and $\pm 2 \% .{ }^{33}$ All results were reproducible and indicated that the proposed methods are robust enough to determine the RUF in pharmaceuticals.

\section{CONCLUSION}

HPLC and UV-visible spectrophotometric methods were appropriate to quantify RUF in pure and pharmaceutical preparations. Therefore, precise and selective HPLC and spectrophotometric methods were developed to estimate RUF in pharmaceutical preparations. Although HPLC is a modern and sophisticated technique, it is expensive and timeconsuming. A narrow range of RUF concentrations $(0.15-3.5 \mu \mathrm{g} /$ $\mathrm{mL}$ ) could be estimated using HPLC. However, the UV-visible spectrophotometric method is easy, inexpensive and performed almost in all quality control and research laboratories. It can also determine various RUF concentrations (10-100 $\mu \mathrm{g} / \mathrm{mL}$ ). The chromatographic method presented sensitive and reliable results with good recoveries. In contrast, the spectrophotometric method offers a simple, accurate, precise, and time-saving method. It could be recommended as an equivalent alternative method. These two methods could be successfully applied to quantify RUF in research laboratories, hospitals, and quality control laboratories.

\section{Ethics}

Ethics Committee Approval: The ethics committee approval is not required for the proposed research. We have not used any human beings or animal matrix.

Informed Consent: Not applicable.

Peer-review: Externally peer-reviewed.

\section{Authorship Contributions}

Concept: H.R., S.M.H., Design: S.M.H., Data Collection or Processing: H.R., Analysis, or Interpretation: H.R., S.M.H., Literature Search: H.R., Writing: H.R., S.M.H.

Conflict of Interest: No conflict of interest was declared by the authors.

Financial Disclosure: The authors declared that this study received no financial support.

\section{REFERENCES}

1. Kim SH, Kang HC, Lee JS, Kim HD. Rufinamide efficacy and safety in children aged 1-4 years with Lennox-Gastaut syndrome. Brain Dev. 2018;40:897-903.

2. Saydam M, Takka S. Bioavailability file: rufinamide. FABAD J Pharm Sci. 2019;44:231-242.

3. Wheless JW, Vazquez B. Rufinamide: a novel broad-spectrum antiepileptic drug. Epilepsy Curr. 2010;10:1-6.

4. Cheng-Hakimian A, Anderson GD, Miller JW. Rufinamide: pharmacology, clinical trials, and role in clinical practice. Int J Clin Pract. 2006;60:14971501. 
5. Kluger G, Glauser T, Krauss G, Seeruthun R, Perdomo C, Arroyo S. Adjunctive rufinamide in Lennox-Gastaut syndrome: a long-term, openlabel extension study. Acta Neurol Scand. 2010;122:202-208.

6. Wisniewski CS. Rufinamide: a new antiepileptic medication for the treatment of seizures associated with lennox-gastaut syndrome. Ann Pharmacother. 2010;44:658-667.

7. The Merck Index. Merck Research Laboratories, $14^{\text {th }}$ edition, (Monograph \#3635), 2006; 621.

8. SC Sweetman (Editor); Martindale. The Complete Drug Reference, $36^{\text {th }}$ edition, The Pharmaceutical Press; London, UK: 2009; 367.

9. McLean AW, Schmutz M, Pozza F. The influence of rufinamide on sodium currents and action potential firing in rodent neurons. Epilepsia. 2005; $46: 296$

10. Perucca E, Cloyd J, Critchley D, Fuseau E. Rufinamide: clinical pharmacokinetics and concentration-response relationships in patients with epilepsy. Epilepsia. 2008;49:1123-1141.

11. Brunner LA, Powell ML. An automated method for the determination of a new potential antiepileptic agent (CGP 33101) in human plasma using high performance liquid chromatography. Biomed Chromatogr. 1992;6:278-282.

12. Rouan MC, Buffet C, Masson L, Marfil F, Humbert H, Maurer G. Practice of solid-phase extraction and protein precipitation in the 96-well format combined with high-performance liquid chromatography-ultraviolet detection for the analysis of drugs in plasma and brain. J Chromatogr B Biomed Sci Appl. 2001;754:45-55.

13. la Marca G, Malvagia S, Filippi L, Innocenti M, Rosati A, Falchi M, Pellacani S, Moneti G, Guerrini R. Rapid assay of rufinamide in dried blood spots by a new liquid chromatography-tandem mass spectrometric method. J Pharm Biomed Anal. 2011;54:192-197.

14. Annapurna MM, Kumar BSP, Goutam SVS, Srinivas L. Stability indicating liquid chromatographic method for the quantitative determination of rufinamide in pharmaceutical dosage forms. J Drug Deliv Ther. 2012;2:167-174.

15. Annapurna M, Goutam, SVS, Saketha CN, Pavani S. New stability indicating liquid chromatographic method for the quantitative determination of rufinamide in presence of degredant products. Drug Invent. Today. 2012;4:501-506.

16. Singh J, Sangwan S, Grover P, Mehta L, Kiran D, Goyal A. Analytical method development and validation for assay of rufinamide drug. J. Pharm. Technol. Res. Managem. 2013;1:191-203.

17. Sai Pavan Kumar B, Mathrusri Annapurna M, Pavani S. Development and validation of a stability indicating RP-HPLC method for the determination of rufinamide. J Pharm Anal. 2013;3:66-70.

18. Harisudha K, Lavanya G, Eswarudu M, Eswaraiah M, Spandana B, Sunil, M. RP-HPLC method development and validation for estimation of rufinamide in bulk and its pharmaceutical dosage form. Int J Res Pharm Chem. 2013;3:392-397.

19. Gáll Z, Vancea S, Dogaru MT, Szilágyi T. Liquid chromatography-mass spectrometric determination of rufinamide in low volume plasma samples. J Chromatogr B Analyt Technol Biomed Life Sci. 2013;940:4246.

20. Ngumo PM, Abuga KO, Njogu PM, Ongarora DSB. A Stability indicating liquid chromatography method for the assay of rufinamide bulk material and tablets. East Cent African J Pharm Sci. 2016;19:16-21.
21. Ranjith, K, Basaveswara Rao MV, Murthy TEGK. Development and validation of related substances method for rufinamide tablets by RPHPLC. J Chem Pharm Res. 2017;9:306-314.

22. Dalvi AV, Uppuluri CT, Bommireddy EP, Ravi PR. Design of experimentsbased RP-HPLC bioanalytical method development for estimation of rufinamide in rat plasma and brain and its application in pharmacokinetic study. J Chromatogr B. 2018;1102-1103:74-82.

23. Baldelli S, Cattaneo D, Giodini L, Baietto L, Di Perri G, D'Avolio A, Clementi E. Development and validation of a HPLC-UV method for the quantification of antiepileptic drugs in dried plasma spots. Clin Chem Lab Med. 2015;53:435-444.

24. Mazzucchelli I, Rapetti M, Fattore C, Franco V, Gatti G, Perucca E. Development and validation of an HPLC-UV detection assay for the determination of rufinamide in human plasma and saliva. Anal Bioanal Chem. 2011;401:1013-1021.

25. Hassib ST, Hashem HMA, Mahrouse MA, Mostafa EA. Development and bio-analytical validation of chromatographic determination method of rufinamide in presence of its metabolite in human plasma. J Chromatogr Sci. 2021;59:458-464.

26. Hassib ST, Hashem HMA, Mahrouse MA, Mostafa EA. Determination of rufinamide in the presence of 1-[(2,6-difluorophenyl) methyl]-1H-1,2,3triazole- 4 carboxylic acid using RP-HPLC and derivative ratio methods as stability indicating assays to be applied on dosage form. J. AOAC Int. 2020;103:1215-1222.

27. Patel A, Patwari A, Suhagia B. Development of a validated stabilityindicating HPTLC method for rufinamide in bulk and its pharmaceutical dosage form. J Chromatogr Sci. 2014;52:1294-1301.

28. Annapurna, MM, Krishna GS, Padmakar B. Novel spectrophotometric methods for the quantitative analysis of rufinamide in pharmaceutical dosage forms. Chem Sci Trans. 2013;2:13-18.

29. Annapurna MM, Kumar BSP, Prakash R, Venkatesh B. New derivative spectrophotometric methods for determination of rufinamide in pharmaceutical dosage forms. Rec Adv Pharm Sci Res. 2012;1:107-111.

30. Muneer S, Ishaq BM, Ruksana H, Ahad HA. A simple UV spectroscopic method for the determination of rufinamide in bulk and tablets. Int J Med Pharm Res. 2015; 3:1041-1044.

31. Jagadeesh P, Srikanth U, Eswarudu MM, Babu PS, Aneesh Sk, Khan PSHR, Pooja SS, Rani KN. New validated extractive spectrophotometric method for the determination of rufinamide in bulk and its pharmaceutical dosage form. Indo Am JP Sci. 2019;6:1798-1805.

32. Patel A, Suhagia B. Extractive spectrophotometric method determination of rufinamide in bulk and its pharmaceutical dosage forms. World $J$ Pharm Sci. 2014;2:176-180.

33. International Conference on Harmonization (ICH) Guidelines Q2 (R1). Validation of Analytical Procedures: Text and Methodology. 2005.

34. Mahamuni BS, Srinivas R, Talluri MVNK. Characterization of forced degradation products of rufinamide by LC/QTOF/MS/MS, NMR and IR studies. Anal Chem Lett. 2018,8:405-415.

35. Perucca E, Cloyd J, Critchley D, Fuseau E. Rufinamide: clinical pharmacokinetics and concentration-response relationships in patients with epilepsy. Epilepsia. 2008;49:1123-1141.

36. Wheless JW, Vazquez B. Rufinamide: a novel broad-spectrum antiepileptic drug. Epilepsy Curr. 2010;10:1-6. 